\title{
Economic growth and convergence: Do institutional proximity and spillovers matter?
}

\author{
Mahyudin Ahmad $^{\mathrm{a} *}$ and Stephen G. Hall ${ }^{\mathrm{b}}$ \\ ${ }^{a}$ Faculty of Economics, University of Cambridge, CB3 9DD Cambridge, United Kingdom; \\ and Universiti Teknologi MARA Malaysia, Arau, 02600 Perlis, Malaysia \\ ${ }^{b}$ University of Leicester, LE1 7RH Leicester, United Kingdom; \\ and University of Pretoria, South Africa
}

(Forthcoming in Journal of Policy Modeling-subject to proofread)

\begin{abstract}
:
This paper extends the existing studies on institutions-growth nexus in two ways: firstly, it estimates a growth model that is spatially augmented to capture the countries' dependence, and secondly it measures the countries' dependence using a newly proposed concept called institutional proximity, in addition to the commonly used geography. Spatial Durbin model, that includes not only spatially lagged dependent variable but also spatially lagged explanatory variables, is shown to be the most appropriate to describe the panel dataset used in this study, which comprises of observations from 58 developing countries for year 1984-2007. The results find that institutions, specifically the property rights institutions, matter for growth in developing countries. The results also find an evidence of indirect institutional spillovers where institutions in a country lead to growth improvement in the country and subsequently generate positive spillover effects on neighbors' economic growth. The results also yield robust support to the concept of augmented convergence process as a result of neighboring effects and its speed is relatively higher than the conventional $\beta$-convergence of a standard growth model. The greater convergence speed is consistent across a number of spatial models using both geographical and institutional proximity measures. The paper finally concludes with several policy implications for developing countries as far as the effects of institutional proximity and spillovers on growth and convergence are concerned.
\end{abstract}

Keywords: Economic growth, convergence, institutional proximity, spillovers, spatial Durbin model.

JEL code: C21, O43, R10

\footnotetext{
* Corresponding author. Email: mahyudin@ perlis.uitm.edu.my or mahyudin_77@yahoo.com ; Tel: +6012-639 6356, Fax: $+604-988$ 2526. The corresponding author gratefully acknowledges the funding from the Ministry of Higher Education, Malaysia for his academic visit to University of Cambridge, United Kingdom (08/2015-07/2017).
} 


\section{Introduction and background}

Institutions matter. The growth literature has arguably already arrived at an academic consensus with strong empirical evidence supporting the significant effect of institutions on cross-country income differences and growth. Empirical studies on growth would typically include institutional variable as one of the determinants and majority of the analyses have shown that institutions are indeed one of the deep-determinants of growth (see for example the influential studies by Acemoglu, Johnson, and Robinson, 2005; Hall and Jones, 1999; Rodrik, Subramanian, and Trebbi, 2004; as well as the institutions-growth studies focusing on developing countries such as that of Addison and BaliamouneLutz, 2006; Alguacil, Cuadros and Orts, 2011; and Kant, 2016). Nevertheless, many economists argue the institutional analysis is still short of a unified analytical framework (Potts, (2007), and more research need to be done before the institutional perspective can be fully operationalized (Efendic, Pugh, and Adnett, 2011).

On another note, numerous evidence on the space's significant relationship to economic growth have also been found. In an excellent survey by Abreu, de Groot, and Florax (2005), they demonstrate a growth process with a spatial relationship, or is spatially dependent, when changes in a particular country's economic growth are determined by factors belonging to not only the country but also the neighbors. Abreu et al. discuss numerous examples of spatially dependent growth experience and subsequently propose an extension to the growth analysis to capture this dependence. Omission of this spatial dependence is expected to cause serious misspecification problem in a standard growth model (see also Anselin and Bera, 1998; Anselin, 2001; and Arbia, 2006).

Example of spatial studies on income differences and growth that take into account the effects of institutions are such as Bosker and Garretsen (2009) and Arbia, Battisti, and Di Vaio (2010). Bosker and Garretsen estimate an extended version of Rodrik et al.'s (2004) baseline model that includes a measure of neighbors' institutional quality, and the results support its significant impact to a home country's GDP per capita. Arbia et al. meanwhile investigate institutional spillovers and growth performance of European regions over the period of 1991-2004 and find country-specific institutions 
are highly significant to regional output per worker. Holding the geographical distance fixed, they show that the growth rates of regions sharing similar institutional characteristics tend to converge more rapidly to each other. Meanwhile, there are also studies investigating the effect of spillovers on growth by Almansour, Aslam, Bluedorn and Duttagupta (2015), on total factors productivity by Fujimori and Sato (2015), as well as on the production process by Dietzenbacher (2000), however none of these studies uses a formal spatial econometrics approach and examines the effect of institutional spillovers.

A convention in the spatial studies, geographical measures of countries' dependence are commonly preferred since geography has been shown to be a good proxy for transportation costs and technological transfers. Additionally, from the spatial econometrics point of view, geographical measures are superior due to its time-invariance and exogeneity advantages that are capable to overcome identification problem. Nevertheless, spatial studies are increasingly becoming the preferred method not only to geographers, but also to economists, political scientists, sociologists, etc. Therefore, the notion of distance may be less meaningful if it is restricted to geography per se.

As a matter of fact, this is an interesting development in the spatial literature as more and more studies are adopting non-geographical measures of spatial dependence to capture network of interactions, appropriate similarities or shared characteristics, and historical ties between the observations. Put differently, the assumption that economies are independent from each other no longer hold as technological transfers, knowledge diffusions, labor migrations, institutional spillovers, contagious economic crises are among the phenomena showing the economies are indeed "interacting" with each other, or in spatial term, they are actually spatially dependent.

On the back of this development, this paper seeks to deepen our understanding on the institutions-growth nexus via a formal spatial econometrics approach using a non-conventional measure of countries' dependence based on the institutional proximity concept. ${ }^{1}$ This concept, which is discussed

\footnotetext{
${ }^{1}$ Institutional proximity actually mirrors the concept of institutional distance, a concept widely researched in the field of international management and international business based on the work of Kostova (1999) and Kostova and Zaheer (1999). They build on the Scott (1995)'s framework outlining three pillars of institutionalism to define institutional distance as the extent to which regulative, cognitive and normative institutions of two countries differ from one another. In our study, we are more interested in a situation where the two countries having greater similarity (i.e. proximity, or less distance) in their relative location in the institutional quality space.
} 
further in the subsequent section, is generally defined as the degree of institutional similarity shared by a number of countries, and this concept is hardly explored in the previous empirical growth studies in either institutional or spatial literatures. This constitutes the paper's main extension from, and an important contribution to, the existing institutions-growth studies.

The main objective of the paper is to investigate the role of institutional proximity and spillovers on economic growth and convergence. Firstly, using an explicit spatial model of growth, this paper seeks to uncover the institutional spillovers and augmented convergence process resulting from the neighbors' effects, defined as the neighboring countries growth-determinants including institutions. Secondly, via the institutional proximity concept, the paper seeks to extend the "neighboring" definition into an institutional perspective and to examine the effect of such proximity on growth and convergence. Eventually the findings of the above are expected to inform policy makers in developing countries their policy decisions regarding growth and convergence. To achieve this objective, the paper estimates a growth model augmented with variables that reflect a number of institutional qualities and a spatial dependence term that connects the countries under study via institutional proximity weighting matrix, in addition to commonly used geographical matrix.

Overall, the paper finds robust evidence to the significant impact of institutions on developing countries economic growth, although it is restricted to property rights institutions only. The findings also show the presence of institutional spillovers in the countries under study, at least indirectly, where an improvement in institutional quality in a country leads to a growth improvement in the country and subsequently to an improvement in the neighbors' growth. Other important finding of the paper is that there is a greater speed of convergence in a spatially modeled growth compared to the $\beta$-convergence in an otherwise standard growth model. Political institutions meanwhile are shown perform empirically well in explaining the institutional proximity concept, and countries with similar polity settings are expected to have an increased spatial dependence between them and eventually converge to similar levels of growth. Finally, some policy implications to improve the developing countries' growth catching-up process are discussed, followed by the study's limitation and caveat. 
The study is organized as follows: this introduction being the first section, Section 2 next presents the institutional proximity concept, the spatial growth model, the spatial weight matrices, and the proposed hypotheses to test. Data and estimation strategy are explained in Section 3. Section 4 discusses the estimation results and Section 5 concludes with some policy implications.

\section{Institutional proximity and augmented convergence speed in a spatial growth model:}

\subsection{Institutional proximity concept:}

This paper, while retaining the focus on the growth-institutions nexus, extends an otherwise a standard empirical growth analysis using a formal spatial econometrics approach that captures the countries' spatial dependence. A non-geographical spatial dependence measure drawn from the concept of institutional proximity is introduced, in addition to the commonly used geographical measure. Since institutions have been empirically shown to be one of the significant growth determinants, naturally it could be postulated that institutionally similar countries may exhibit higher tendency to have economic interactions with each other, and eventually to achieve comparable growth levels and greater spillovers between them.

Thus, apart from testing for the usability of non-geographical measure of dependence in a formal spatial econometrics study, this paper intends to find an evidence to the above postulation and to show that the spatial interactions and spillovers are not because of the countries' closer geographical location, although this can be one of the reasons, but are essentially promoted by the shared institutional characteristics, or greater institutional proximity, of the countries. By using institutional proximity as a measure of spatial dependence in the analysis of the countries' growth process, the findings are expected to give an important insight into the developing countries' strategies to improve their convergence to the growth levels of the higher-income nations. This is since developing countries are naturally presumed to have somewhat lower quality of institutions as compared to the higher-income countries which are often characterized by better quality of institutions. 
To make institutional proximity concept clearer to readers, some taxonomy adjustments to the concept of spatial heterogeneity and spatial dependence first introduced by Abreu, de Groot, and Florax (2005) are made. Abreu et al. refer spatial heterogeneity to the notion when parameters in growth model vary depending on their locations. This is possible if disturbances in growth regressions are correlated across space, since the omitted variables (such as climate, institutions and technology) contain some element of spatial dimension. ${ }^{2}$ If these omitted variables are possible to be observed, their growth-effect will be captured by including their proxy variables in the model. If they are not, a solution to this problem is to include country dummies as a proxy for these variables. Spatial dependence, on the other hand, occurs when the observations in one location depend on the values of observations at other locations. For example, growth rates of a country surrounded by politically unstable countries may be lower due to negative spillovers in the form of refugees, lower foreign direct investment and disruption to trade routes. Similarly, clusters of high performing countries could also spur growth-promoting factors in nearby country because of policy imitations, knowledge spillovers and high-skilled labor migration.

To incorporate an institutional perspective into the above concepts, firstly, spatial heterogeneity is replaced with institutional heterogeneity thereby indicating that institutions would typically vary across spatial units, and the institutional variations are captured by including a specific variable to control for institutions in the growth regression. Secondly, the concept of institutional dependence, which is equivalent to spatial dependence, is rephrased to institutional proximity. This is to reflect countries' spatial dependence which is now determined by their institutional similarity, and no longer by their geographical locations.

\subsection{Spatial growth model with augmented convergence speed:}

A conventional spatial growth model is one where, in addition to the normal explanatory variables, there are also growth-effects from the distance of the countries in the model. A logical argument would suppose that countries which are located closer may behave in a similar way, and a

\footnotetext{
${ }^{2}$ For instance, the effects of tariffs on growth may be greater for countries located in coastal areas when compared to landlocked countries.
} 
way that is different to distant countries e.g. countries in Europe vs. in Africa. As is earlier mentioned, if a country is experiencing civil wars, regime changes and political coups, these situations would definitely give adverse effects to the neighboring countries' economic development due to increased number of refugees, reduced foreign investments, disrupted trade routes, etc. The proposed institutional proximity concept nevertheless argues that location is more than geography, and there is no reason why these spatial effects should be restricted purely to geographical distance.

Anselin (2002) argues that geographical distance may not be able to capture the other kind of distances that also play a major role in shaping the economic relationship across space. Similarly, Beck, Gleditsch and Beardsley (2006) show that in many political science studies interdependence between the countries can be defined by social or political phenomena such as historically shared ties or levels of interactions. Meanwhile, Ertur and Koch (2011) suggest that definition of connectivity is in fact much broader than geography and can be generalized to any network structure reflecting any kind of interactions between observations. Arbia et al. (2010) meanwhile argue that non-conventional spatial matrix based on institutional proximity (in their word, institutional heterogeneity) is crucial because this matrix is capable to capture the distance beyond the geographical notion that still play an important role in shaping the economic behavior both at micro and macro levels.

To this end, this paper thus intends to find evidence that institutional proximity i.e., the countries "relative location" in the institutional quality space, is indeed an important determinant of the growth convergence and spillovers. ${ }^{3}$

Consider a simple growth model based on Barro (1991) as follows:

$$
g_{t}=\alpha+\beta \log y_{0}+X \theta+\varepsilon
$$

\footnotetext{
${ }^{3}$ From econometrics point of view, the intuition behind this argument is that the errors in a panel growth regression contain, at least in part, all the misspecification and omitted variables in the model. Institutional quality is often hard to measure and so any index of quality must be subjected to problems which will be reflected in the errors of the model. It is therefore expected that countries sharing similarity in an institutional sense would exhibit similar errors. This is the essence of the institutionalspatial growth model proposed in this study.
} 
where $g_{t}=\Delta \log y_{t}$ which is an $N x l$ vector of real GDP per capita growth rates, $\alpha$ is an $N x l$ vector of constant terms, $\log y_{0}$ is an $N x l$ vector of logs of real GDP per capita at the beginning of the period, $X$ is an $N x k$ matrix of explanatory variables, $\beta$ is the convergence coefficient, $\theta$ is $K x l$ vector of parameters, and $\varepsilon \sim N\left(0, \sigma^{2} I\right)$ is an $N x I$ vector of i.i.d. error terms. $\beta$ is the conventional convergence parameter of the countries under study and it is expected to be negative to reflect the catching-up process by the countries to their steady state levels. A set of explanatory variables $X$ is added as steady state determinants and following Mankiw, Romer and Weil (1992) stock of physical capital ( $s k$, human capital $(s h)$ and a term $(n+g+\delta)$, that accounts for the sum of population growth, exogenous technological change, and depreciation rate respectively, are included. To capture the effects of institutional heterogeneity on growth, indices of institutional quality namely the property rights index and the political institutions index are included as part of the explanatory variables $X$.

To account for spatial dependence in the growth model of Equation (1), a spatial autoregressive error term is commonly used as a starting point:

$$
\varepsilon=\lambda W \varepsilon+u
$$

where $W$ is an $N x N$ spatial weight matrix capturing the interdependence (or connectivity) between countries under study, $\lambda$ is a spatial autoregressive parameter, $\varepsilon$ is an $N x 1$ vector spatially correlated errors, and $u$ is an $N x l$ vector of a spatial disturbance term with i.i.d. properties. Assuming the inverse $(I-\lambda W)^{-1}$ exists, and combining Equation (2) with Equation (1), a reduced form equation can be written as:

$$
g=\alpha+\beta \ln y_{0}+X \theta+(I-\lambda W)^{-1} u
$$

where $I$ is the $N x I$ identity matrix. Equation (3) is considered a spatial error model (SEM) of growth where the spatial effect operates via shocks to the growth process. SEM renders the spatial dependence a "nuisance" factor which rather makes the spatial effects a relatively less important in the model (Arbia 
et al. 2010). To model a more substantive effect of the spatial relationship between countries, Equation (3) above can be rearranged into:

$$
g=\alpha+\beta \log y_{0}+X \theta+\lambda W g+\phi W \log y_{0}+\vartheta W X+u
$$

where $\alpha$ is vector of constants i.e. $\alpha(1-\lambda W)$, and $\phi=-\lambda \beta$ and $\vartheta=-\lambda \theta$. In Equation (4) transforms SEM into Spatial Durbin Model (SDM) which contains a spatially lagged dependent variable and spatially lagged explanatory variables. SDM thus is a model that takes into account two spatial relationships: firstly, the spatial relationship in the dependent variables, which refers to the growth rate in a country that is assumed to depend, in part, to weighted average of the neighboring countries growth rates (in Equation (4), this is captured by the spatially lagged dependent variable term, $\lambda W g$ ), and secondly, the spatial relationship between the growth rates in a country and the explanatory variables in neighboring countries, which indicates the growth rates in the country depends, in part, on the weighted average of growth determinants in neighboring countries (in Equation (4), this is captured by the spatially lagged explanatory variables term, $\vartheta W X$ and spatially lagged initial income term, $\left.\phi W \log y_{0}\right)$.

The two terms, $\phi=-\lambda \beta$ and $\vartheta=-\lambda \theta$ become are the restrictions for Equation (4) and these restrictions enable us to test for the spatial dependence in the growth model whether it is a nuisance factor that runs via error structure only (i.e. when the terms $\lambda, \phi$ and $\vartheta$ in Equation (4) representing the substantive spatial effects are equal to zero, the appropriate model is thus SEM in Equation (3)) or a substantive effect that directly influences growth via the spatially lagged dependent variable and the spatially lagged explanatory variables (which makes SDM in Equation (4) as the appropriate model). The test for these restrictions is discussed more in the next section.

It is worth mentioning that the spatial Durbin growth model in Equation (4) above allows for the augmented convergence speed to be determined. Recall that the convergence speed in a conventional growth model is given by the convergence coefficient, $\beta$, taking the partial derivative of the GDP per capita growth with respect to the initial GDP per capita. On the other hand, in a growth model that is spatially augmented with neighbors' growth-determinants and initial GDP per capita, the convergence 
coefficient is then transformed into an augmented partial derivative. Specifically, the spatial Durbin model in Equation (4) can be rearranged into a form that allows for the augmented convergence be determined, as the following:

$$
g=(1-\lambda W)^{-1}\left(\alpha+\beta \log y_{0}+X \theta+\phi W \log y_{0}+\vartheta W X+u\right)
$$

Taking partial derivative of GDP per capita growth with respect to the initial GDP per capita from the Equation (5) above gives the following:

$$
\partial g / \partial \log y_{0}=(1-\lambda W)^{-1}(\beta I+\phi W)
$$

and the augmented convergence coefficient can be determined as the following: ${ }^{4}$

$$
(1+\lambda) \beta+\phi
$$

With the presence of $\lambda$ and $\phi$ terms in Equation (7) above, the convergence speed is now augmented with the neighboring effects, in other words, the speed of convergence in a spatial model is shown to be greater than a normal $\beta$-convergence due to the spatial dependence effects.

\subsection{Incorporating institutional proximity into spatial growth model:}

As is introduced in Equation (2) above, $W$ is the $N x N$ weight matrix to measure the spatial dependence or connectivity between the countries under study. This matrix determines the degree of "nearness" or the proximity which in turn influences the size of spatial spillovers across countries. Spatial econometrics has its roots in geography, so naturally the weighting matrix in spatial studies is specified via geographical notion of distance, such as physical distance, contiguity measures, $k$-nearest regions, or a more complex distance decay function. Geographical matrix typically assumes the countries that are located closely would have a greater weight, or more spatial dependence between them, compared to the countries located farther. The advantage of geographical matrix is that it is

\footnotetext{
${ }^{4}$ We follow Arbia et al. (2010) to decompose $(1-\lambda W)^{-1}$ into $\sum_{i=o}^{\infty} \lambda^{i} W^{i}=I+\lambda W+\lambda^{2} W^{2}+\lambda^{3} W^{3}+\ldots$ and to round the effects to first order only with the assumption that the effect of higher order spatial terms rapidly approaching zero.
} 
unambiguously exogenous to the model, and therefore it eliminates the problem of identification and causal reversion.

As is previously discussed, the institutional proximity concept argues that location is more than geography, and there is no reason why these spatial spillovers should be restricted purely to geographical distance. In addition to the commonly used geographical matrix, this study also uses a non-conventional matrix based on the institutional proximity concept, which is the matrix of interest in this study. The exogenous geographical matrix that is capable to overcome identification problem in growth model shall acts as a control measure against which the endogenous institutional proximity matrix is benchmarked. Explanation on the matrices used are as the following:

Firstly, the geographical matrix, namely an inverse squared distance matrix (denoted winvsq). ${ }^{5}$ The elements in this matrix are defined according to a gravity function that provides an exponential distance decay, thus, the spatial relationship is modelled according to the concept of impedance, or distance decay. This means all features influence all other features, but the farther away something is, the smaller the impact it has. Because every feature is a neighbor of every other feature, a cut-off distance is specified to reduce the number of required computations due to large datasets and it is set at a minimum threshold which guarantees that each country has at least one neighbor. The matrix $W$ winvsq is given by:

$$
W\left\{\begin{array}{c}
w_{i j}=0 \quad \text { if } i=j \\
w_{i j}=d_{i j}^{-2} / \sum_{j} d_{i j}^{-2} \quad \text { if } d_{i j}^{-2} \leq \overline{d^{-2}} \\
w_{i j}=0 \text { if otherwise }
\end{array}\right.
$$

\footnotetext{
${ }^{5}$ We use latitude and longitude data to compute the Great Circle distance between countries' capitals i.e. the shortest distance between any two points on the surface of a sphere measured along a path on the surface of the sphere (as opposed to going through the sphere's interior). It is computed using the equation:

$$
d_{i j}=\arccos \left[\left(\sin \phi_{i} \sin \phi_{j}\right)+\left(\cos \phi_{i} \cos \phi_{j} \cos |\delta \gamma|\right)\right]
$$

where $\phi_{i}$ and $\phi_{j}$ are the latitude of country $i$ and $j$ respectively, and $|\delta \gamma|$ denotes the absolute value of the difference in longitude between country $i$ and $j$ (Seldadyo et al. 2010).
} 
where $d_{i j}$ is the great circle distance between country's capital $i$ and $j$, and $\bar{d}$ is the critical distance cutoff after which the spatial effects are considered negligible. The elements in the main diagonal are set to zero by convention since a country cannot be a neighbor to itself. Since the data used in this study consists of $i=1$ to $n=58$ countries, and the corresponding countries' capitals to calculate the distance is also $j=1$ to $k=58$, and the time period is $t=1984$ to $T=2007$, the inverse distance weight matrix for a particular year, $t$, will be:

$$
W_{t}=\left(\begin{array}{ccccc}
0 & w_{t, i j} & \ldots & \ldots & w_{t, i k} \\
w_{t, j i} & 0 & \ldots & \ldots & w_{t, j k} \\
\vdots & \vdots & \ddots & & \vdots \\
\vdots & \vdots & & \ddots & \vdots \\
w_{t, j n} & w_{t, i n} & \ldots & \ldots & 0
\end{array}\right)
$$

and stacking the matrix first by time and then by cross section gives the full weighting matrix as:

$$
W=\left(\begin{array}{ccccc}
W_{t} & 0 & \ldots & \ldots & 0 \\
0 & W_{t+2} & \ldots & \ldots & 0 \\
\vdots & \vdots & \ddots & & \vdots \\
\vdots & \vdots & & \ddots & \vdots \\
0 & 0 & \ldots & \ldots & W_{T}
\end{array}\right)
$$

with a dimension of $58 * 24 \times 58 * 24$ i.e. $1392 \times 1392$.

Secondly, the matrix derived from the concept of institutional proximity generated via Kogut and Singh (1988) cultural distance index calculation as the following:

$$
C D=\frac{\sum_{i=1}^{n}\left[\left(I_{i j}-I_{i k}\right)^{2} / V_{i}\right]}{n}
$$

where $I_{i j}$ is the index value for cultural dimension $i$ for country $j, I_{i k}$ is the index value for cultural dimension $i$ for country $k, V_{i}$ is the variance of the index of the cultural dimension $i$, and $n$ is the number of cultural dimension $i$. In this study, the cultural dimension is replaced with institutional dimension, and there are four institutional dimensions based on four institutional variables used to create an institutional proximity matrix. 
Two institutional proximity matrices are generated. First, it is called property right matrix (denoted wicrg) constructed from four property right institutions variables obtained from the International Country Risk Guide (ICRG) dataset (The PRS Group, 2009). The other is called political institutions matrix (denoted wpol) constructed from four political institutions variables obtained from four different sources (the variables to construct both matrices are discussed more in the data sources section next). These institutional proximity matrices are computed for each year throughout the sample period of 24 years and then stacked together to complete the full weighting matrix as in Equation (10).

As is earlier discussed, the primary motivation of this study is to find evidence on the significant effects of institutions and institutional proximity on the countries' growth and convergence process. If, say, the degree of institutional proximity between two countries is greater, i.e. both countries are more similar institutionally, the spatial dependence between them is expected to be higher. In the empirical estimation of spatial growth model of Equation (4), greater size of spatial coefficients ( $\lambda, \phi$ and $\vartheta$ ) can be expected due to larger neighbors' effects (neighbors in this case are the countries that have similar institutional characteristics -i.e. countries located closer in the institutional quality space). As a result, the augmented convergence speed too is expected to be greater compared to the countries that are institutionally dissimilar (recall Equation (7) where $\lambda$ and $\phi$ are the spatial terms that reflect neighboring effects in the augmented convergence speed).

The institutional variables to construct the property right and political institutions matrices have a range of scores and the score may change over the years indicating the change in the quality of the institutions. Suppose that an institutional quality related to property rights or polity settings in a particular country has improved during the period under study (the score increases), it means the distance to higher quality institutions has reduced, or the degree of similarity is now greater between the institutions in the country experiencing improvement to the (high income) countries having already attained better quality institutions (already have higher scores). The above situation undoubtedly makes an interesting case on the effects of increased institutional similarity on growth and convergence, 
regardless of the countries' geographical locations. Therefore, the use of institutional proximity matrices is indeed crucial to achieve the paper's primary objective.

Nevertheless, we acknowledge the issue of endogeneity in the institutional proximity matrices due to the use of time-varying institutional variables to construct the matrices. Nevertheless, and as is earlier stated, to mitigate the endogeneity issue in the institutional matrices, the results of the estimations using the institutional proximity matrices wicrg and wpol are benchmarked against the exogenous geographical matrix winvsq.

\subsection{The proposed testable hypotheses:}

Building from the preceding discussions on the spatial growth model, the augmented convergence speed, the conceptual definitions of institutional proximity and its incorporation into the spatial growth model, the following testable hypotheses are proposed:

Hypothesis 1: Institutions matter for economic growth (to test for institutional heterogeneity)

Hypothesis 2: Convergence speed is greater when growth is spatially modeled (to test for augmented convergence speed)

Hypothesis 3: Institutional proximity matter for growth convergence (to test for institutional proximity concept)

\section{Data sources and estimation strategy}

The dataset used in this study consists of panel observations for 58 developing countries in three regions namely Africa, East Asia, and Latin America for a 24-year period 1984-2007. The dataset is a balanced panel; $n=58$ and $t=24$ and total observations $N T=1392$. Data on real GDP per capita and population growth are obtained from World Development Indicators (WDI) from the World Bank (2009). Following Caselli, Esquivel, and Lefort (1996), Hoeffler (2002), Islam (1995), and Mankiw et al. (1992), exogenous technological change plus depreciation rate $(g+\delta)$ is assumed at 0.05 , and investment share of real per capita GDP is used as a proxy for capital. The data for investment share are obtained from Penn World Table 6.3 (Heston et al. 2009). To proxy for human capital, secondary school attainment for population age 15 and above variable from Barro and Lee (2010) is used. 
To test for institutions' significant effects on growth, two institutional indices are included in the growth model. First, an index of institutional quality that reflects the security of property rights (denoted iiqicrg), derived from a simple average of four variables namely Investment Profile, Law and Order, Bureaucracy Quality and Government Stability, obtained from the ICRG. Second, an index of institutional quality that reflects the political institutions (iiqpol), which is also a simple average of four democracy variables, namely Polity 2 variable from Polity IV dataset (Marshall and Jaggers, 2008), Political rights variable from Freedom in the World index (Gastil, 1978), Polcon 3 from The Political Constraint Index dataset (Henisz, 2010), and Checks variable from Database of Political Institutions by the World Bank (Beck et al. 2001).

The four ICRG variables to derive property rights index and the four democracy variables to derive political institutions index above are subsequently used in the construction of the property rights (wicrg) and political institutions (wpol) matrices, respectively. However, it is worth mentioning that the institutional quality indices, meant to capture the countries' institutional heterogeneity, are obtained using a simple average calculation, whereas the institutional matrices, meant to reflect the degree of institutional proximity, are based on the cultural distance index calculation of Equation (11), that concerns more on the differences in the institutional variables between countries.

To estimate the growth model of Equation (4), four different specifications are used, all with real GDP per capita growth $(g)$ as the dependent variable, and log of initial income (log $\left.y_{1984}\right)$ as the variable to test for the convergence effect. Model (1) is a baseline model with only Mankiew, et al. (1992) variables namely physical capital $(s k)$, human capital $(s h)$, and a sum of population growth, exogenous technological change and depreciation rate $(n+g+\delta)$-henceforth called MRW variables. Model (2) and (3) introduce institutional quality indices iiqicrg and iiqpol, respectively, in addition to MRW variables, and finally in Model (4), which is the general model, all MRW variables and both institutional indices are included in the model specification.

The empirical analysis begins with testing for the spatial autocorrelation in the model. Equation (1) is estimated via Ordinary Least Square (OLS) and the presence of spatial autocorrelation in the 
residuals is tested using Moran's I test. If Moran's I test is significant, indicating the presence of spatial autocorrelation in the error terms, OLS is no longer appropriate. ${ }^{6}$ The commonly suggested maximum likelihood regression technique is consequently used to overcome this problem (Elhorst 2003).

Subsequently, Lagrange Multiplier (LM) test is used to test for the appropriate form of spatial model either spatial error model or spatial lag model. The spatial error model is identical to the Equation (2) where the spatial dependence is restricted to the model's random shock only. Meanwhile, the spatial lag model assumes the spatial dependence is substantive, meaning that a country's growth is not only influenced by the within-country determinants but also by the neighbors' growth level, and this is captured by the inclusion of a spatial lag term (the term $\lambda W g$ in Equation (4)) in the model. A more substantive process can be modelled via an "extended" spatial lag model namely spatial Durbin model that includes not only spatial lag term $\lambda W g$, but also a spatially lagged initial income $\phi W \log y_{o}$ and a number of spatially lagged explanatory variables, $\vartheta W X$.

LeSage and Pace (2009) argue that the spatial Durbin model is the best point to begin the test since the cost of omitting the spatially autocorrelated error term is less (the estimators loses efficiency only) compared to the cost of ignoring the spatially lagged dependent and independent variables (the estimators are biased and inconsistent). However, Florax et al. (2003) argue that using spatial lag model, conditional on the results of misspecification tests, outperforms the general-to-specific approach for finding the true data generating process.

In this study, two-stage testing procedure is used to determine the model that best fits the data. In the first stage, robust LM test developed by Anselin et al. (1996) is used to decide which model between spatial error or spatial lag that is more appropriate for the data. The used of "robust" LM test is necessary because the existence of one more type of spatial dependence does not bias the test for the other type of spatial dependence. This feature is important because a spatial model is omitted when it fails this test in most cases (when it is estimated with different specifications and matrices). The model

\footnotetext{
${ }^{6}$ If the true model that best fits the data is spatial error model, the OLS estimates of the parameter remains unbiased, but it loses its efficiency property, but if the true model is spatial lag model, the OLS estimates are not only biased, but also inconsistent.
} 
that succeeds in the first stage LM test is subsequently tested against the general model (the spatial Durbin model) in the second stage using Likelihood Ratio (LR) test for the spatial common factors, which is as the following:

$$
L R=2\left(L_{u r}-L_{r}\right) \sim \chi^{2}(k)
$$

This test, which is based on Elhorst (2010), Elhorst and Fréret (2009), and Seldadyo et al. (2010), assumes the spatial Durbin model as the unrestricted model, and the restricted model is either the spatial lag or spatial error model that succeeds in the first stage LM test.

\section{Estimation results and discussions}

Table 1 presents the OLS regression results for the four growth specifications based on Equation (1). The stylized facts on the presence of conditional convergence in developing countries are supported as the coefficient for initial income is consistently negative and statistically significantly different from zero, and the coefficients for growth determinants are also statistically significant with the expected signs. However, population growth is found to be positive, nevertheless this finding is not uncommon especially in developing countries. Headey and Hodge (2009) find no strong support for the negative-effect of population growth.

The result of Moran's I test in Table 1 indicates the null hypothesis of no spatial autocorrelation in the OLS residuals is overwhelmingly rejected. This finding holds across different model specifications and matrices. Equation (1) is therefore misspecified and the OLS estimates are invalid. Consequently, the model shall be modified to include a spatial dependence term. From the first-stage robust LM test statistics, spatial error model is apparently inappropriate as it fails in a number of cases (specifically in model 2 and 4) compared to spatial lag model. Meanwhile, the second-stage LR tests statistics for the common factors between spatial lag and spatial Durbin model as in Table 2 indicate that spatial Durbin model is favored over spatial lag model. 
Table 1: Standard OLS growth regression and Moran's I test for spatial autocorrelation in residuals

\begin{tabular}{|c|c|c|c|c|}
\hline Model specification & (1) & $(2)$ & $(3)$ & $(4)$ \\
\hline \multirow[t]{2}{*}{$\log y_{1984}$} & $-0.008 * * *$ & $-0.009 * * *$ & $-0.009 * * *$ & $-0.009 * * *$ \\
\hline & $(0.0015)$ & $(0.0015)$ & $(0.0015)$ & $(0.0016)$ \\
\hline \multirow[t]{2}{*}{$s k$} & $0.029 * * *$ & $0.025 * * *$ & $0.028 * * *$ & $0.024 * * *$ \\
\hline & $(0.0026)$ & $(0.0026)$ & $(0.0026)$ & $(0.0027)$ \\
\hline \multirow[t]{2}{*}{$n+g+\delta$} & $0.012 * * *$ & $0.011 * * *$ & $0.012 * * *$ & $0.011 * * *$ \\
\hline & $(0.0016)$ & $(0.0016)$ & $(0.0016)$ & $(0.0016)$ \\
\hline \multirow[t]{2}{*}{$s h$} & $0.001 * * *$ & $0.001 * * *$ & $0.001 * * *$ & $0.001 * * *$ \\
\hline & $(0.000)$ & $(0.000)$ & $(0.001)$ & $(0.000)$ \\
\hline \multirow[t]{2}{*}{ iiqicrg } & & $0.008 * * *$ & & $0.009 * * *$ \\
\hline & & $(0.001)$ & & $(0.001)$ \\
\hline \multirow[t]{2}{*}{ iiqpol } & & & $0.002 * * *$ & $0.001^{*}$ \\
\hline & & & $(0.001)$ & $(0.001)$ \\
\hline \multirow[t]{2}{*}{ constant } & $-0.115 * * *$ & $-0.126 * * *$ & $-0.118 * * *$ & $-0.136 * * *$ \\
\hline & $(0.017)$ & $(0.017)$ & $(0.017)$ & $(0.017)$ \\
\hline Adjusted R2 & 0.136 & 0.176 & 0.140 & 0.170 \\
\hline \multicolumn{5}{|c|}{ Moran's I and Robust LM tests statistics for different weight matrix: } \\
\hline \multicolumn{5}{|c|}{ a. $\operatorname{winvsq}$} \\
\hline Moran's I test statistics & $5.185^{* * *}$ & $4.884 * * *$ & $4.901 * * *$ & $4.744 * * *$ \\
\hline Spatial error: Robust LM test & $40.286 * * *$ & 1.768 & $34.930 * * *$ & 2.53 \\
\hline Spatial lag: Robust LM test & $67.543 * * *$ & $12.168 * * *$ & $59.907 * * *$ & $14.229 * * *$ \\
\hline \multicolumn{5}{|l|}{ b. wicrg } \\
\hline Moran's I test statistics & $5.197 * * *$ & $3.163 * * *$ & $4.989 * * *$ & $3.316 * * *$ \\
\hline Spatial error: Robust LM test & $10.533 * * *$ & 0.339 & $9.123 * * *$ & 0.005 \\
\hline Spatial lag: Robust LM test & $25.030 * * *$ & $2.346 * * *$ & $23.107 * * *$ & 0.788 \\
\hline \multicolumn{5}{|l|}{ c. wpol } \\
\hline Moran’s I test statistics & $2.735 * * *$ & $2.690 * * *$ & $2.667 * * *$ & $2.854 * * *$ \\
\hline Spatial error: Robust LM test & $19.620 * * *$ & 1.448 & $14.704 * * *$ & 0.076 \\
\hline Spatial lag: Robust LM test & $28.111 * * *$ & $5.082 * *$ & $20.793 * * *$ & 1.494 \\
\hline
\end{tabular}

Notes: Dependent variable is real GDP per capita growth. Model specification (1) is baseline model with only MRW variables i.e. $s h$, $s k$, and $n+g+\delta$, model (2) with MRW variables and iiqicrg, (3) with MRW variables and iiqpol, and (4) with MRW variables, and both iiqicrg and iiqpol indices. Standard errors are in parentheses. $* * *, * *$ and $*$ denote significance at $1 \%, 5 \%$ and $10 \%$ respectively.

Table 2: Likelihood ratio test between spatial Durbin and spatial lag model

\begin{tabular}{|c|c|c|c|c|}
\hline Model specification & $(1)$ & $(2)$ & (3) & $(4)$ \\
\hline \multicolumn{5}{|l|}{ Weight matrix : winvsq } \\
\hline Log Likelihood for Spatial Lag Model & 2147.774 & 2174.9646 & 2150.1035 & 2176.4316 \\
\hline Log Likelihood for Spatial Durbin Model & 2170.784 & 2199.866 & 2172.502 & 2200.386 \\
\hline Degree of freedom & 4 & 5 & 5 & 6 \\
\hline LR test statistics & $46.019 * * *$ & $49.803 * * *$ & $44.796 * * *$ & $47.909 * * *$ \\
\hline \multicolumn{5}{|l|}{ Weight matrix: wicrg } \\
\hline Log Likelihood for Spatial Lag Model & 2143.543 & 2166.474 & 2146.435 & 2168.521 \\
\hline Log Likelihood for Spatial Durbin Model & 2154.703 & 2167.873 & 2155.825 & 2169.568 \\
\hline Degree of freedom & 4 & 5 & 5 & 6 \\
\hline LR test statistics & $22.319 * * *$ & 2.799 & $18.782 * * *$ & 2.0928 \\
\hline \multicolumn{5}{|l|}{ Weight matrix: wpol } \\
\hline Log Likelihood for Spatial Lag Model & 2135.607 & 2167.036 & 2137.966 & 2168.453 \\
\hline Log Likelihood for Spatial Durbin Model & 2147.660 & 2174.854 & 2148.113 & 2175.203 \\
\hline Degree of freedom & 4 & 5 & 5 & 6 \\
\hline LR test statistics & $24.106 * * *$ & $15.634 * * *$ & $20.295 * * *$ & $13.499 * *$ \\
\hline
\end{tabular}

Notes: Please refer Table 1 footnote for information about Model (1) until (4). ***, ** and * denote significance at $1 \%, 5 \%$ and $10 \%$ respectively. 
Now we come to the important part: interpretation of the results of Spatial Durbin model of Equation (4) estimated using three different weight matrices namely inverse squared distance (winvsq), property rights matrix (wicrg), and political institutions matrix (wpol), and the results are presented in Table 3, 4 and 5, respectively. Overall, the results support the conditional convergence stylized facts, as the initial income coefficients are always negative and significant across all estimations, the coefficients of the steady state growth determinants namely physical and human capitals are also positive and significant. The effect of population growth on economic growth remains positive, similar to the OLS results. Another important finding that sets the stage for the use of Spatial Durbin as the most appropriate spatial model is Wald test 2 where the null hypothesis that the coefficients of spatially lagged initial income and spatially lagged explanatory variables equal to zero is rejected in majority of the specifications. This test thus reinforces the previous second-stage LR test that shows the spatial Durbin as the most appropriate model to explain the data.

The effect of institutional quality indices iiqicrg and iiqpol on growth apparently mirrors the results in the OLS regression, as iiqicrg index is always significant in the specifications it appears, but iiqpol index is not. Nevertheless, the significance of iiqicrg index is quite sensitive to the choice of weight matrix, i.e. only when the geography matrix winvsq and political institutions matrix wpol are used, but not when the property rights matrix wicrg is used. This study therefore finds only a partial empirical support to Hypothesis 1, i.e. institutions does matter for economic growth in developing countries, but this is only restricted to property rights institutions. Political institutions on the other hand have no significant growth-effect.

To find empirical support for Hypothesis 2 regarding the augmented convergence speed in a spatially modeled growth, we first examine at the coefficient of the spatially lagged dependent variable $\lambda$. The results indicate a positive and significant $\lambda$ across all specifications using three matrices including the institutional matrices, at minimum $10 \%$ significance level. Furthermore, Wald test 1 of the null hypothesis of $\lambda=0$ is overwhelmingly rejected in all estimations. This finding therefore gives convincing support to the proposition of positive spillovers of economic growth amongst the developing 
countries. Since positive growth-effect of institutional quality index is reported in the preceding paragraph, although it is only in the case of property rights institutions, the finding of positive significant $\lambda$ therefore confirms the existence of positive institutional spillovers between the countries, at least indirectly, where institutions in a country cause an increase in economic growth in the country (the positive growth-effect of institutions) and this situation subsequently generates a positive spillover effect to neighbors' economic growth (positive spatial dependence). This finding is largely similar to Easterly and Levine (1998), Ades and Chua (1997), Murdoch and Sandler (2002), Bosker and Garretsen (2009) and Arbia et al. (2010).

Next, we proceed to the calculation of the size of augmented convergence speed using Equation (7). The calculation shows the speed is indeed higher than the conventional $\beta$-convergence obtained from the OLS growth regression. In Table 3 when the geography matrix wicrg is used, the convergence speed rises to $1.9-2.2 \%$ from $0.8-0.9 \%$ when it is estimated using a standard growth model (see OLS growth regression in Table 1). This finding thus confirms the significant neighbors' effect on the convergence speed as earlier proposed in Hypothesis 2, and shows that geographically closer countries tend to converge faster to similar levels of growth.

Interestingly, the convergence speed in the spatial estimation using political institutions matrix wpol is also greater than that of standard growth estimation; see the convergence speed of around 1.2$1.5 \%$ in Table 5 which is greater than the $\beta$-convergence (log $y_{1984}$ coefficient) in Table 1 ranging between from $0.8-0.9 \%$. This finding strengthens the earlier evidence for Hypothesis 2 and at the same time undoubtedly gives a robust empirical support to Hypothesis 3 that institutional proximity does matter for growth convergence. Specifically, the results show that countries sharing similar political institutions characteristics would have greater convergence speed and eventually converge to similar levels of growth. Besides, the estimation using political institutions matrix wpol (Table 5) apparently gives identical results to the estimation using exogenous geography matrix winvsq (Table 3).

This results too continue to support our earlier findings on the presence of indirect institutional spillovers, although in now the countries' proximity is measured in term of their relative location in the 
institutional quality space, and not in term of their geographical locations. Recall that earlier we find the spatially lagged dependent variable, $\lambda$, is significant across all estimations using different matrices including the political institutions matrix wpol.

On the other hand, the results from the spatial growth estimation using property rights matrix wicrg in Table 4 show that the speed of convergence around $0.5-0.9 \%$ is lower than the conventional $\beta$-convergence in Table 1 that is around $0.8-0.9 \%$. Theoretically, it has been shown that a spatially modelled growth would always have greater convergence speed since it is augmented with the neighbors' effects (see Equation (7) the augmented convergence coefficient of $(1+\lambda) \beta+\phi$ is clearly greater than the conventional $\beta$-convergence in the standard growth model). Based on these results, and the findings in the preceding paragraph when political institutions matrix wpol is used, it can be plausibly assumed that property right matrix wicrg is less robust than the political institutions matrix wpol. As an additional evidence that property rights matrix wircg is the weaker matrix of the two, recall the results in Table 4 when both institutional quality indices iiqicrg and iiqpol are not significant and the Wald test 2 for the significant spatially lagged initial income and spatially lagged explanatory variables fails in two out of four specifications.

Several other interesting results are also noteworthy. The results show that spatially lagged initial income, $\phi W \log y_{o}$ are insignificant in almost all growth estimations using the three matrices (see results for $\left.w_{-} \log y_{1984}\right)$. One particular reason in explaining the insignificance of spatially lagged initial income is that the locations of the developing countries, due to their proximity in geographical or institutional space, generate spillover effects that operate via spatially lagged growth only (since we find significant $\lambda$ ), and not via the spatially lagged initial income. This situation could be a result of dissimilar long run growth determinants for the developing countries under study (see Abreu et al. 2005 and Arbia et al. 2010 for more discussion in this regard).

The findings nevertheless show positive significant spatial externalities of the physical and human capitals (wx_sk and $w x_{-} s h$ respectively), which indicates the significant spillovers of the physical and human capitals across countries. This finding is similar to Lall and Yilmaz (2001) who 
find human capital spillovers using data for the United States, and to López-Bazo et al. (2004) who find technological diffusion across the EU regions. Similarly, Ertur and Koch $(2006 ; 2007)$ estimate a spatially augmented Solow model and find evidence of technological spillovers, and spatial externalities of physical (2007) and human capitals (2006). Again, the consistently significant spillovers of physical and human capitals are restricted to the estimations using geography matrix winvsq and political institutions matrix wpol only.

Meanwhile, the presence of direct institutional spillovers (here, direct is defined as institutional quality of neighbors affecting the home country's growth), captured by the coefficient of wx_iiqicrg and wx_iiqpol, are not robustly supported. Property rights spillovers, wx_iiqicrg, are significant in all specifications using the geography matrix winvsq and political matrix wpol, but not the property rights wicrg. On the other hand, the political spillovers wx_iiqpol are insignificant in almost all estimations. Nevertheless, contrary to the previously documented positive indirect spillovers of institutions towards growth (significant property rights index iiqicrg coupled with significant coefficient of spatially lagged dependent variable, $\lambda$ ) as well as the similar results from Easterly and Levine 1998; Ades and Chua 1997; Murdoch and Sandler 2002; Bosker and Garretsen 2009; and Arbia et al. 2010, we find negative direct spillovers of property rights index wx_iiqicrg.

In the hindsight, these contradictory findings could be thought as a result of endogeneity setback plaguing the use of institutional weight matrices, but a closer inspection of the estimation using exogenous geography matrix winvsq in Table 3 finds similar negative direct spillovers property rights index which tells us that the institutional matrix's endogeneity is not a major concern here. After all, this study is not the first to find no empirical support for the positive direct spillover of institutions as Faber and Gerritse (2009) and Claeys and Manca (2011) also report the similar findings. 
Table 3: Spatial Durbin regression of growth model using inverse squared distance weight matrix (winvsq)

\begin{tabular}{|c|c|c|c|c|}
\hline Model specification & (1) & $(2)$ & (3) & (4) \\
\hline $\log y_{1984}$ & $\begin{array}{c}-0.0058 * * * \\
(0.0014)\end{array}$ & $\begin{array}{c}-0.010 * * * \\
(0.0018)\end{array}$ & $\begin{array}{c}-0.0059 * * * \\
(0.0015)\end{array}$ & $\begin{array}{c}-0.0099 * * * \\
(0.0018)\end{array}$ \\
\hline$s k$ & $\begin{array}{c}0.0184 * * * \\
(0.0029)\end{array}$ & $\begin{array}{c}0.0137 * * * \\
(0.0030)\end{array}$ & $\begin{array}{c}0.0179 * * * \\
(0.0029)\end{array}$ & $\begin{array}{c}0.0135 * * * \\
(0.0031)\end{array}$ \\
\hline$n+g+\delta$ & $\begin{array}{c}0.0146 * * * \\
(0.0055)\end{array}$ & $\begin{array}{c}0.0138 * * \\
(0.0054)\end{array}$ & $\begin{array}{c}0.0147 * * * \\
(0.0055)\end{array}$ & $\begin{array}{c}0.0138 * * \\
(0.0054)\end{array}$ \\
\hline$s h$ & $\begin{array}{c}0.0008 * * * \\
(0.0001)\end{array}$ & $\begin{array}{c}0.0006 * * * \\
(0.0001)\end{array}$ & $\begin{array}{c}0.0007 * * * \\
(0.0001)\end{array}$ & $\begin{array}{c}0.0006 * * * \\
(0.0001)\end{array}$ \\
\hline iiqicrg & & $\begin{array}{c}0.0093 * * * \\
(0.0021)\end{array}$ & & $\begin{array}{c}0.0091 * * * \\
(0.0021)\end{array}$ \\
\hline iiqpol & & & $\begin{array}{c}0.0010 \\
(0.0007)\end{array}$ & $\begin{array}{c}0.0005 \\
(0.0006)\end{array}$ \\
\hline$\lambda$ & $\begin{array}{c}0.1749 * * \\
(0.0705)\end{array}$ & $\begin{array}{c}0.2038 * * * \\
(0.0700)\end{array}$ & $\begin{array}{c}0.1802 * * \\
(0.0701)\end{array}$ & $\begin{array}{c}0.2057 * * * \\
(0.0699)\end{array}$ \\
\hline$w_{-} \log y_{1984}$ & $\begin{array}{c}-0.0150 * * * \\
(0.0051)\end{array}$ & $\begin{array}{c}-0.0080 \\
(0.0056)\end{array}$ & $\begin{array}{c}-0.0143 * * * \\
(0.0051)\end{array}$ & $\begin{array}{c}-0.0073 \\
(0.0057)\end{array}$ \\
\hline$w x \_s k$ & $\begin{array}{c}0.0408^{* * *} * \\
(0.0087) \\
\end{array}$ & $\begin{array}{c}0.0429 * * * \\
(0.0089)\end{array}$ & $\begin{array}{c}0.0442 * * * \\
(0.0091)\end{array}$ & $\begin{array}{c}0.0445 * * * \\
(0.0090)\end{array}$ \\
\hline$w x \_n+g+\delta$ & $\begin{array}{c}0.0056 \\
(0.0088) \\
\end{array}$ & $\begin{array}{c}0.0035 \\
(0.0087) \\
\end{array}$ & $\begin{array}{c}0.0031 \\
(0.0089) \\
\end{array}$ & $\begin{array}{c}0.0020 \\
(0.0090) \\
\end{array}$ \\
\hline$w x \_s h$ & $\begin{array}{c}0.0013 * * * \\
(0.0005)\end{array}$ & $\begin{array}{c}0.0016 * * \\
(0.0006)\end{array}$ & $\begin{array}{c}0.0014 * * * \\
(0.0005)\end{array}$ & $\begin{array}{c}0.0016 * * * \\
(0.0006)\end{array}$ \\
\hline$w x \_i i q i c r g$ & & $\begin{array}{c}-0.0123 * * * \\
(0.0041)\end{array}$ & & $\begin{array}{c}-0.0118 * * * \\
(0.0042)\end{array}$ \\
\hline$w x \_$iiqpol & & & $\begin{array}{l}-0.0040^{*} \\
(0.0024)\end{array}$ & $\begin{array}{c}-0.0023 \\
(0.0025) \\
\end{array}$ \\
\hline constant & $\begin{array}{l}-0.1978^{*} \\
(0.1092) \\
\end{array}$ & $\begin{array}{l}-0.1805^{*} \\
(0.1018) \\
\end{array}$ & $\begin{array}{l}-0.1821^{*} \\
(0.1090) \\
\end{array}$ & $\begin{array}{l}-0.1737 * \\
(0.1025) \\
\end{array}$ \\
\hline Augmented convergence speed & -0.0218 & -0.0200 & -0.0213 & -0.0192 \\
\hline Squared Correlation & 0.1844 & 0.2164 & 0.1864 & 0.2169 \\
\hline Variance Ratio & 0.1849 & 0.2160 & 0.1862 & 0.2164 \\
\hline Log likelihood & 2170.784 & 2199.866 & 2172.502 & 2200.386 \\
\hline Wald test 1 & $6.160 * *$ & $8.476 * * *$ & $6.606 * * *$ & $8.665 * * *$ \\
\hline Wald test 2 & $31.386 * * *$ & $30.522 * * *$ & $34.904 * * *$ & $32.253 * * *$ \\
\hline $\mathrm{N}$ & 1392 & 1392 & 1392 & 1392 \\
\hline
\end{tabular}

Notes: Dependent variable is real GDP per capita growth. Please refer Table 1 footnote for information about Model (1) until (4). Standard errors are in parentheses. Wald test 1 is for null hypothesis that $\lambda=0 \sim \chi 2(1)$. Wald test 2 is for null hypothesis that coefficients of spatial lags of $\mathrm{X}^{\prime} \mathrm{s}=0 \sim \chi 2(1) . * * *, * *$ and $*$ denote significance at $1 \%, 5 \%$ and $10 \%$ respectively. 
Table 4: Spatial Durbin regression of growth model using institutional distance weight matrix (wicrg)

\begin{tabular}{|c|c|c|c|c|}
\hline Model specification & $(1)$ & (2) & (3) & (4) \\
\hline $\log y_{1984}$ & $\begin{array}{c}-0.0079 * * * \\
(0.0014)\end{array}$ & $\begin{array}{c}-0.0087 * * * \\
(0.0016)\end{array}$ & $\begin{array}{c}-0.0084 * * * \\
(0.0014)\end{array}$ & $\begin{array}{c}-0.0093 * * * \\
(0.0017)\end{array}$ \\
\hline$s k$ & $\begin{array}{c}0.0270 * * * \\
(0.0031)\end{array}$ & $\begin{array}{c}0.0249 * * * \\
(0.0032)\end{array}$ & $\begin{array}{c}0.0265 * * * \\
(0.0030)\end{array}$ & $\begin{array}{c}0.0243 * * * \\
(0.0032)\end{array}$ \\
\hline$n+g+\delta$ & $\begin{array}{c}0.0124 * * \\
(0.0052)\end{array}$ & $\begin{array}{c}0.0115^{* *} \\
(0.0052)\end{array}$ & $\begin{array}{c}0.0127 * * \\
(0.0052)\end{array}$ & $\begin{array}{c}0.0117 * * \\
(0.0052)\end{array}$ \\
\hline$s h$ & $\begin{array}{c}0.0007 * * * \\
(0.0001)\end{array}$ & $\begin{array}{c}0.0006 * * * \\
(0.0001)\end{array}$ & $\begin{array}{c}0.0007 * * * \\
(0.0001)\end{array}$ & $\begin{array}{c}0.0006^{* * * *} \\
(0.0001)\end{array}$ \\
\hline iiqicrg & & $\begin{array}{c}0.0058 \\
(0.0038) \\
\end{array}$ & & $\begin{array}{c}0.0062 \\
(0.0042) \\
\end{array}$ \\
\hline iiqpol & & & $\begin{array}{c}0.0011 \\
(0.0007)\end{array}$ & $\begin{array}{l}0.0013 * \\
(0.0007)\end{array}$ \\
\hline$\lambda$ & $\begin{array}{c}0.2097 * * * \\
(0.0684)\end{array}$ & $\begin{array}{c}0.1610 * * \\
(0.0677)\end{array}$ & $\begin{array}{c}0.2097 * * * \\
(0.0680)\end{array}$ & $\begin{array}{c}0.1609 * * \\
(0.0674)\end{array}$ \\
\hline$w_{-} \log y_{1984}$ & $\begin{array}{c}0.0042 \\
(0.0052) \\
\end{array}$ & $\begin{array}{c}0.0020 \\
(0.0054) \\
\end{array}$ & $\begin{array}{c}0.0039 \\
(0.0052) \\
\end{array}$ & $\begin{array}{c}0.0017 \\
(0.0057) \\
\end{array}$ \\
\hline$w x \_s k$ & $\begin{array}{l}-0.0001 \\
(0.0112)\end{array}$ & $\begin{array}{c}-0.0070 \\
(0.0103)\end{array}$ & $\begin{array}{c}0.0005 \\
(0.0113)\end{array}$ & $\begin{array}{c}-0.0063 \\
(0.0102)\end{array}$ \\
\hline$w x \_n+g+\delta$ & $\begin{array}{c}0.0051 \\
(0.0059)\end{array}$ & $\begin{array}{c}0.0039 \\
(0.0057)\end{array}$ & $\begin{array}{c}0.0050 \\
(0.0059)\end{array}$ & $\begin{array}{c}0.0035 \\
(0.0059)\end{array}$ \\
\hline$w x \_s h$ & $\begin{array}{c}0.0013^{* * *} \\
(0.0004)\end{array}$ & $\begin{array}{c}0.0005 \\
(0.0004)\end{array}$ & $\begin{array}{c}0.0013^{* * * *} \\
(0.0004)\end{array}$ & $\begin{array}{c}0.0005 \\
(0.0004)\end{array}$ \\
\hline$w x \_i i q i c r g$ & & $\begin{array}{c}0.0015 \\
(0.0058)\end{array}$ & & $\begin{array}{c}0.0012 \\
(0.0064)\end{array}$ \\
\hline$w x \_$iiqpol & & & $\begin{array}{c}-0.0005 \\
(0.0016)\end{array}$ & $\begin{array}{l}-0.0010 \\
(0.0018)\end{array}$ \\
\hline constant & $\begin{array}{c}-0.2125 * * * \\
(0.0661) \\
\end{array}$ & $\begin{array}{c}-0.1651 * * \\
(0.0672) \\
\end{array}$ & $\begin{array}{c}-0.2099 * * * \\
(0.0659) \\
\end{array}$ & $\begin{array}{c}-0.1583^{* *} \\
(0.0667) \\
\end{array}$ \\
\hline Augmented convergence speed & -0.0054 & -0.0081 & -0.0063 & -0.0091 \\
\hline Squared Correlation & 0.1649 & 0.1818 & 0.1661 & 0.1838 \\
\hline Variance Ratio & 0.1603 & 0.1821 & 0.1618 & 0.1841 \\
\hline Log likelihood & 2154.703 & 2167.874 & 2155.826 & 2169.568 \\
\hline Wald test 1 & $9.408 * * *$ & $5.653 * *$ & $9.499 * * *$ & $5.706^{* *}$ \\
\hline Wald test 2 & $19.991 * * *$ & 2.539 & $18.387 * * *$ & 2.200 \\
\hline $\mathrm{N}$ & 1392 & 1392 & 1392 & 1392 \\
\hline
\end{tabular}

Notes: Dependent variable is real GDP per capita growth. Please refer Table 1 note for information about Model (1) until (4). Standard errors are in parentheses. Wald test 1 is for null hypothesis that $\lambda=0 \sim \times 2(1)$. Wald test 2 is for null hypothesis that coefficients of spatial lags of $X^{\prime} \mathrm{s}=0 \sim \chi 2(1) . * * * * *$ and $*$ denote significance at $1 \%, 5 \%$ and $10 \%$ respectively. 
Table 5: Spatial Durbin regression of growth model using institutional distance weight matrix (wpol)

\begin{tabular}{|c|c|c|c|c|}
\hline Model specification & (1) & (2) & (3) & (4) \\
\hline $\log y_{1984}$ & $\begin{array}{c}-0.0085 * * * \\
(0.0014)\end{array}$ & $\begin{array}{c}-0.0102 * * * \\
(0.0015)\end{array}$ & $\begin{array}{c}-0.0082 * * * \\
(0.0014)\end{array}$ & $\begin{array}{c}-0.0099 * * * \\
(0.0015)\end{array}$ \\
\hline$s k$ & $\begin{array}{c}0.0289 * * * \\
(0.0031)\end{array}$ & $\begin{array}{c}0.0240 * * * \\
(0.0031)\end{array}$ & $\begin{array}{c}0.0290 * * * \\
(0.0031)\end{array}$ & $\begin{array}{c}0.0241 * * * \\
(0.0031)\end{array}$ \\
\hline$n+g+\delta$ & $\begin{array}{c}0.0134 * * * \\
(0.0052)\end{array}$ & $\begin{array}{c}0.0122 * * \\
(0.0052)\end{array}$ & $\begin{array}{c}0.0133 * * \\
(0.0052)\end{array}$ & $\begin{array}{c}0.0121 * * \\
(0.0051)\end{array}$ \\
\hline$s h$ & $\begin{array}{c}0.0008 * * * \\
(0.0001)\end{array}$ & $\begin{array}{c}0.0006 * * * \\
(0.0001)\end{array}$ & $\begin{array}{c}0.0008 * * * \\
(0.0001)\end{array}$ & $\begin{array}{c}0.0006 * * * \\
(0.0001)\end{array}$ \\
\hline iiqicrg & & $\begin{array}{c}0.0084 * * * \\
(0.0018)\end{array}$ & & $\begin{array}{c}0.0084 * * * \\
(0.0018)\end{array}$ \\
\hline iiqpol & & & $\begin{array}{c}-0.0024 \\
(0.0030)\end{array}$ & $\begin{array}{c}-0.0015 \\
(0.0031) \\
\end{array}$ \\
\hline$\lambda$ & $\begin{array}{l}0.1145^{*} \\
(0.0644) \\
\end{array}$ & $\begin{array}{c}0.1287 * * \\
(0.0622) \\
\end{array}$ & $\begin{array}{l}0.1111 * \\
(0.0645) \\
\end{array}$ & $\begin{array}{c}0.1268 * * \\
(0.0624) \\
\end{array}$ \\
\hline$w_{-} \log y_{1984}$ & $\begin{array}{c}-0.0051 \\
(0.0036)\end{array}$ & $\begin{array}{c}-0.0020 \\
(0.0036)\end{array}$ & $\begin{array}{c}-0.0038 \\
(0.0039)\end{array}$ & $\begin{array}{c}-0.0009 \\
(0.0038)\end{array}$ \\
\hline$w x \_s k$ & $\begin{array}{c}0.0160 * * \\
(0.0074)\end{array}$ & $\begin{array}{c}0.0190 * * * \\
(0.0072)\end{array}$ & $\begin{array}{c}0.0176 * * \\
(0.0077) \\
\end{array}$ & $\begin{array}{c}0.0211 * * * \\
(0.0074)\end{array}$ \\
\hline$w x \_n+g+\delta$ & $\begin{array}{c}0.0063 \\
(0.0061) \\
\end{array}$ & $\begin{array}{c}0.0046 \\
(0.0058) \\
\end{array}$ & $\begin{array}{c}0.0055 \\
(0.0062) \\
\end{array}$ & $\begin{array}{c}0.0036 \\
(0.0059)\end{array}$ \\
\hline$w x \_s h$ & $\begin{array}{c}0.0011 * * * \\
(0.0003)\end{array}$ & $\begin{array}{c}0.0007 * * \\
(0.0003)\end{array}$ & $\begin{array}{c}0.0011 * * * \\
(0.0003)\end{array}$ & $\begin{array}{c}0.0007 * * \\
(0.0003)\end{array}$ \\
\hline wx_iiqicrg & & $\begin{array}{l}-0.0048 * \\
(0.0028) \\
\end{array}$ & & $\begin{array}{l}-0.0050 * \\
(0.0027) \\
\end{array}$ \\
\hline$w x \_i i q p o l$ & & & $\begin{array}{c}0.0021 \\
(0.0035)\end{array}$ & $\begin{array}{c}0.0008 \\
(0.0036)\end{array}$ \\
\hline constant & $\begin{array}{c}-0.2050 * * * \\
(0.0774)\end{array}$ & $\begin{array}{c}-0.1915 * * \\
(0.0825)\end{array}$ & $\begin{array}{c}-0.2115 * * * \\
(0.0778)\end{array}$ & $\begin{array}{c}-0.1951 * * \\
(0.0826)\end{array}$ \\
\hline Augmented convergence speed & -0.0146 & -0.0135 & -0.0129 & -0.0121 \\
\hline Squared Correlation & 0.1601 & 0.1916 & 0.1608 & 0.1922 \\
\hline Variance Ratio & 0.1602 & 0.1920 & 0.1608 & 0.1923 \\
\hline Log likelihood & 2147.660 & 2174.854 & 2148.113 & 2175.203 \\
\hline Wald test 1 & $3.162 *$ & $4.289 * *$ & $2.966^{*}$ & $4.124 * *$ \\
\hline Wald test 2 & $20.557 * * *$ & $16.654 * * *$ & $20.130 * * *$ & $16.581 * *$ \\
\hline $\mathrm{N}$ & 1392 & 1392 & 1392 & 1392 \\
\hline
\end{tabular}

Notes: Dependent variable is real GDP per capita growth. Please refer Table 1 note for information about Model (1) until (4). Standard errors are in parentheses. Wald test 1 is for null hypothesis that $\lambda=0 \sim \chi 2(1)$. Wald test 2 is for null hypothesis that coefficients of spatial lags of $X^{\prime} \mathrm{s}=0 \sim \chi 2(1) . * * * * *$ and $*$ denote significance at $1 \%, 5 \%$ and $10 \%$ respectively.

\section{Concluding remarks and policy implications}

This study revisits the institutions-growth nexus and estimates a growth model using a set of balanced panel observations for 58 countries for a period of 24 years from 1984-2007. An important 
contribution by this study is to incorporate an analysis of the countries' spatial dependence into a formal growth study, and the dependence is not only measured via the commonly used geography but also via the newly-proposed institutional proximity concept hitherto has been rarely explored be it in growth or space literatures.

Several findings of this study are noteworthy. Firstly, as a result of the spatial modeling of growth process, the convergence speed of the countries is shown to be greater than the conventional $\beta$ convergence in a standard growth model. The convergence speed in a spatial growth model is apparently augmented with neighbors' factors; neighbors in this case are defined either by the countries' closer geographical locations or by the countries' greater institutional proximity.

Secondly, the study finds the presence of indirect institutional spillovers between the countries under study i.e. institutions in a country improve its economic growth and subsequently generate a similar positive effect on neighbors' growth. This finding, although similar to that of Easterly and Levine (1998), Ades and Chua (1997), Murdoch and Sandler (2002), Bosker and Garretsen (2009), and Arbia et al. (2010) who largely measure the countries proximity via geographical locations, interestingly consistently holds when the proximity is measured via institutional characteristics, specifically the political institutions. This finding thus gives an evidence to the usability of institutional proximity matrix, in our case the political institutions matrix, in a formal spatial growth model to measure the degree of dependence between countries.

An important policy implication from the above findings is that, while policy-makers in a lowincome country, say, in African region could not do anything as far as the geographical location is concerned, since an African country is normally presumably surrounded by a number of similar lowincome countries, apparently something could be done as far as the institutional proximity is concerned. Since the above findings show that the convergence speed is augmented with the spatial effects emanating from the greater similarity of the countries' political characteristics, which include the degree of democracy, political rights and constraints, and check and balance, consequently policy makers in the developing countries may direct their attention and effort towards improving those characteristics 
to a level similar to that of higher-income nations. When this is attained, the two countries with relatively similar political characteristics are then expected to have greater economic interactions and positive spillovers between them and eventually to converge to similar levels of growth.

Finally, and extending the existing evidence on the significant growth-effects of institutions, this study shows that institutional quality reflecting the security of property rights does matter for developing countries' growth. Since the property rights index is comprised of variables capturing various characteristics of an environment of low-risk investments, strong and impartial legal system, a stable government and an efficient bureaucracy, these aspects in our opinion shall also be the focus of the policy makers in developing countries when devising their institutions-building strategies.

Nevertheless, and apart from the indirect institutional spillovers previously shown, the above results apparently do not fully support the presence of direct mechanisms through which the institutional spillovers may occur. On the other hand, the results are able to show the presence of significant physical and human capital externalities which are directly affecting neighbors' growth and independently of the indirect institutional spillovers mechanism. More research are undoubtedly necessary to explore and identify other possible mechanisms of institutional spillovers that may generate a more direct effect, and to achieve this, interesting proximity features like trade relationship, cultural proximity, network of interactions, etc. can be used as a proxy for institutional proximity.

Finally, there is an important caveat in the policy implications discussed above in term of the differentiation between institutions and policy (see detailed discussion on this by Rodrik, 2007). Often there are situations where the developing countries' poor institutions continue to persist without any significant improvement, masked by the superficial policy changes, eventually resulting in the ineffective institutional spillovers with negligible increase in the growth convergence. Besides, it is arguably much more difficult to implement the required shifts towards good institutions than to formulate a sound policy. Therefore, policy makers need to be mindful of their objectives either it is the long-winding process of institutions-building or a short to medium term policy remedies to the routine economic situations. 


\section{References}

Abreu, M., de Groot, H. L. F., \& Florax, R. J. G. M. (2005). Space and Growth: A Survey of Empirical Evidence and Methods. Region et Developement, 21, 12-43.

Acemoglu, D., Johnson, S., \& Robinson, J. A. (2005). Institutions as a Fundamental Cause of Long-Run Growth, Handbook of Economic Growth Vol. 1, pp. 385-472.

Addison, T. \& Baliamoune-Lutz, M. (2006). Economic reform when institutional quality is weak: The case of Maghreb. Journal of Policy Modeling 28, 1029-1043

Ades, A., \& Chua, H. B. (1997). Thy Neighbour's Curse: Regional Instability and Economic Growth. Journal of Economic Growth, 2(3), 279-304.

Alguacil, M., Cuadros, A. \& Orts, V. (2011). Inward FDI and growth: The role of macroeconomic and institutional environment. Journal of Policy Modeling 33, 481-496.

Almansour, A., Aslam, A., Bluedorn, J. \& Duttagupta, R. (2015). How vulnerable are emerging markets to external shocks. Journal of Policy Modeling 37, 460-483.

Anselin, L. (2001). Spatial econometrics. In B. H. Baltagi (Ed.), A Companion to Theoretical Econometrics (pp. 310-330). Oxford: Blackwell.

Anselin, L., \& Bera, A. (1998). Spatial dependence in linear regression models with an introduction to spatial econometrics In A. Ullah \& D. E. A. Giles (Eds.), Handbook of Applied Economic Statistics (pp. 237-289). New York: Marcel Dekker.

Anselin, L., Bera, A., Florax, R., \& Yoon, M. (1996). Simple diagnostic tests for spatial dependence. Regional Science and Urban Economics, 26(1), 77-104.

Arbia, G. (2006). Spatial Econometrics. Statistical Foundations and Applications to Regional Convergence. Berlin: Springer.

Arbia, G., Battisti, M., \& Di Vaio, G. (2010). Institutions and geography: Empirical test of spatial growth models for European regions. Economic Modelling, 27(1), 12-21.

Barro, R. J. (1991). Economic-growth in a cross-section of countries. Quarterly Journal of Economics, 106(2), 407-443.

Barro, R. J., \& Lee, J.-W. (2010). A New Data Set of Educational Attainment in the World, 1950-2010. National Bureau of Economic Research Working Paper Series, No. 15902.

Beck, N., Gleditsch, K. S., \& Beardsley, K. (2006). Space is more than geography: Using spatial econometrics in the study of political economy. International Studies Quarterly, 50, 27-44.

Bosker, M., \& Garretsen, H. (2009). Economic development and the geography of institutions. Journal of Economic Geography, 9(3), 295-328.

Caselli, F., Esquivel, G., \& Lefort, F. (1996). Reopening the Convergence Debate: A New Look at Cross-Country Growth Empirics. Journal of Economic Growth, 1(3), 363-389.

Claeys, P., \& Manca, F. (2010). A missing spatial link in institutional quality. Applied Economics Letters, 18(3), $223-227$.

Dietzenbacher, E. (2000). Spillovers of innovation effects. Journal of Policy Modeling 22(1), 27-42.

Easterly, W., \& Levine, R. (1998). Troubles with the Neighbours: Africa's Problem, Africa's Opportunity. Journal of African Economies, 7(1), 120-142.

Elhorst, J. P. (2003). Specification and Estimation of Spatial Panel Data Models. International Regional Science Review, 26(3), 244-268.

Elhorst, J. P. (2010). Applied Spatial Econometrics: Raising the Bar. Spatial Economic Analysis, 5(1), 9-28.

Elhorst, J. P., \& Fréret, S. (2009). Evidence Of Political Yardstick Competition In France Using A Two-Regime Spatial Durbin Model With Fixed Effects. Journal of Regional Science, 49(5), 931-951.

Ertur, C., \& Koch, W. (2006). Convergence, Human Capital and International Spillovers: Laboratoire d'Economie et de Gestion, CNRS UMR 5118, Université de Bourgogne.

Ertur, C., \& Koch, W. (2007). Growth, technological interdependence and spatial externalities: theory and evidence. Journal of Applied Econometrics, 22(6), 1033-1062.

Ertur, C., \& Koch, W. (2011). A contribution to the theory and empirics of Schumpeterian growth with worldwide interactions. Journal of Economic Growth, 16, 215-255.

Faber, G., \& Gerritse, M. (2009). External influences on local institutions: spatial dependence and openness: Utrecht School of Economics.

Florax, R. J. G. M., Folmer, H., \& Rey, S. J. (2003). Specification searches in spatial econometrics: the relevance of Hendry's methodology. Regional Science and Urban Economics, 33(5), 557-579.

Fujimori, A. \& Sato, T. (2015). Productivity and technology diffusion in India: The spillover effects from foreign direct investment. Journal of Policy Modeling 37, 630-651. 
Gastil, R. D. (1978). Freedom in the World index: political rights and civil liberties. Retrieved from http://www.nsd.uib.no/macrodataguide/set.html?id=17\&sub=1

Hall, R. E., \& Jones, C. I. (1999). Why do some countries produce so much more output per worker than others? Quarterly Journal of Economics, 114(1), 83-116.

Headey, D. D., \& Hodge, A. (2009). The Effect of Population Growth on Economic Growth: A Meta-Regression Analysis of the Macroeconomic Literature. Population and Development Review, 35(2), 221-248.

Henisz, W. J. (2010). Political Constraint Index Dataset. from http://wwwmanagement.wharton.upenn.edu/henisz/

Hoeffler, A. (2002). The Augmented Solow Model and the African Growth Debate. Oxford Bulletin of Economics and Statistics, 64(2), 135-158.

Islam, N. (1995). Growth Empirics: A Panel Data Approach. The Quarterly Journal of Economics, 110(4), 11271170.

Kant, C. (2016). Are institutions in developing countries malleable? Journal of Policy Modeling 38, 272-289.

Kogut, B., \& Singh, H. (1988). The Effect of National Culture on the Choice of Entry Mode. Journal of International Business Studies, 19(3), 411-432.

Kostova, T. (1999). Transnational Transfer of Strategic Organizational Practices: A Contextual Perspective. The Academy of Management Review, 24(2), 308-324.

Kostova, T., \& Zaheer, S. (1999). Organizational Legitimacy under Conditions of Complexity: The Case of the Multinational Enterprise. The Academy of Management Review, 24(1), 64-81.

Lall, S. V., \& Yilmaz, S. (2001). Regional economic convergence: Do policy instruments make a difference? The Annals of Regional Science, 35(1), 153-166.

LeSage, J., \& Pace, R. K. (2009). Introduction to Spatial Econometrics. Boca Raton, Florida: Chapman \& Hall/CRC.

López-Bazo, E., Vayá Valcarce, E., \& Artis, M. (2004). Regional Externalities and Growth: Evidence from European Regions. Journal of Regional Science, 44(1), 43-73.

Mankiw, N. G., Romer, D., \& Weil, D. N. (1992). A Contribution to the Empirics of Economic Growth. The Quarterly Journal of Economics, 107(2), 407-437.

Marshall, M. G., \& Jaggers, K. (2008). Polity IV Project: Political Regime Characteristics and Transitions, 18002008. from http://www.systemicpeace.org/polity/polity4.htm

Murdoch, J. C., \& Sandler, T. (2002). Economic Growth, Civil Wars, and Spatial Spillovers. Journal of Conflict Resolution, 46(1), 91-110.

PRS Group, T. (2009). International Country Risk Guide dataset.

Rodrik, D., Subramanian, A., \& Trebbi, F. (2004). Institutions rule: The primacy of institutions over geography and integration in economic development. Journal of Economic Growth, 9(2), 131-165.

Rodrik, D. (2007). One Economics Many recipes. Princeton, NJ: Princeton University Press.

Scott, W. R. (1995). Institutions and Organizations: Theory and Research. Thousand Oaks CA: Sage.

Seldadyo, H., Elhorst, J. P., \& Haan, J. D. (2010). Geography and governance: Does space matter? Papers in Regional Science, 89(3), 625-640. 